\title{
Of Darwin and Other Demons: the Evolutionary Turn in Aesthetics
}

\section{KEY WORDS}

evolutionary aesthetics, philosophical aesthetics, beauty, sexual selection, environmental aesthetics, reductionism

\begin{abstract}
Seghers Eveline, Of Darwin and Other Demons: the Evolutionary Turn in Aesthetics 10 Darwinie i innych demonach: zwrot ewolucyiny w estetyce]. Kultura - Społeczeństwo - Edukacja nr 2(8), 2015, Poznań 2015, pp. 73-90, Adam Mickiewicz University Press. ISBN 978-83232-3004-5. ISSN 2300-0422
\end{abstract}

Evolutionary aesthetics attempts to explain the human ability to perceive objects, conspecifics and the surrounding environment in an aesthetic manner - i.e. in an emotional and evaluative way resulting in a positive or negative appraisal - by referring to the evolutionary history of our functional, cognitive make-up. Research has mostly focussed on aesthetic considerations made during landscape assessment and on the role of aesthetic elements during mate choice. Criticism has been expressed repeatedly as to the naturalistic, presumed to be reductionist methods and outlook of an evolutionary approach to aesthetics. This paper briefly reviews the outline of evolutionary aesthetics research and discusses three such critiques - functionality in beauty judgement, reductionism, and the recognition of cultural and interindividual differences. It argues that philosophical aesthetics is not in danger of being unjustly reduced to a neurobiological explanation of aesthetic judgement and experience, and that evolutionary and traditional humanities approaches can be complementary in understanding our sense of beauty.

\section{Introduction}

In 1973, the evolutionary biologist Theodosius Dobzhansky uttered the now famous phrase that "nothing in biology makes sense except in the light of evolution." In recent decades, humanities departments worldwide have similarly recognized the importance of evolutionary theory and its many applications for 
understanding human nature and its cultural products. While presumably less rigorous than evolutionary theory's steady presence in biology departments few humanities scholars will argue that their subjects do not make sense at all when approached from more familiar disciplinary perspectives such as history and philosophy - bio-evolutionary approaches are nonetheless becoming increasingly prevalent in departments that represent some of the most remarkable cultural exponents of human nature.

Yet the advent of evolutionary biology and its related fields has not been unnoticed, and has often been met with significant controversy. Critics tend to focus heavily on the assumption that considering features of biological evolution is a strongly reductionist method, devaluing elements such as cultural significance and semantics. Such critiques are, however, more often than not a reflection of disciplinary conservatism, sparked by insufficient insight into the theoretical structure and explanatory intent of evolutionary theory. This paper addresses the common hostility within humanities departments with regard to biological theorization concerning their subjects by discussing the emergence of evolutionary aesthetics. After briefly sketching the aims and methods of this discipline, it mentions three concerns that have been expressed with regard to evolutionary aesthetics' methods, aims and findings: research in this field is said to be at odds with predominantly Kantian thought in western philosophical aesthetics, it is critized for being overly reductionist because of its naturalistic outlook, and finally, it is supposedly unable to account for interindividual differences in aesthetic preference.

\section{Evolutionary aesthetics: the story of an emerging paradigm}

Historically, the emergence of evolutionary aesthetics almost coincides with the formulation of Darwinian evolutionary theory in On the Origin of Species in 1859. In the mid 19th century, the philosopher and scientist Herbert Spencer already hypothesized that art and aesthetics might have emerged from other, functional behaviours related to survival and reproduction (Aiken, 1999). Important foundations of the discipline were also laid down in the experimental psychological research of Gustav Theodor Fechner, who developed an empirical, bottom-up perspective to aesthetics. His perspective attempted to discover 'laws of liking', focussing on finding objective properties involved in aesthetic judge- 
ment, rather than a definition of beauty, or the normative implications of such judgements (Allesch, 2001).

Methodologically, evolutionary aesthetics is firmly rooted in the discipline of evolutionary psychology. ${ }^{1}$ Researchers in this field argue that the mental structures and operations characteristic of a species, such as humans, have arisen according to evolutionary processes that are similar, if not the same, than in biological evolution. During the Pleistocene epoch, spanning the majority of the evolutionary history of the human lineage, ancestral humans were confronted with a variety of adaptive problems, ranging from having to find and secure suitable mates, determine whether a new environment was suitable to spend more time in, map social interactions, assess cooperative and cheater intent in conspecifics, avoid ingesting harmful substances and provide adequate infant care. These problems created selection pressures which eventually resulted in functional psychological machinery designed to address them. Human nature can, according to many evolutionary psychologists, be regarded as an evolved, species-typical collection of such mechanisms (e.g. Symons, 1992; Thornhill, 2003).

Generally, evolutionary aesthetics researchers propose that the human aesthetic sense - our ability to express negative or positive evaluative judgement of the surrounding environment - reflects such innate cognitive machinery that evolved for a functional purpose (Thornhill, 2003). This function is best understood by referring to evolutionary psychology's general explanation for the evolution of emotions. Emotions are thought to have evolved as motivational systems for directing behaviour. A particular emotional experience by an individual is the eventual outcome of an evolved system of neural rewards and punishments (Orians, 2001; Thornhill, 2003). Throughout evolutionary history, elements in the environment that were beneficial for survival and reproductive purposes were endowed with favourable neural response following sensory perception by an individual, whereas elements that were potentially harmful resulted in neural

\footnotetext{
${ }^{1}$ Evolutionary psychology refers here to the classic Santa Barbara account, endorsed by authors such as John Tooby, Leda Cosmides, Steven Pinker, Donald Symons, etc. (See, for example, Cosmides, Tooby \& Barkow, 1992). Other authors have criticized some of the premises of this classic version of evolutionary psychology, such as the emphasis on massive mental modularity, and the concept of the Environment of Evolutionary Adaptedness (EEA), and the role of culture in psychological and behavioural evolution (Dunbar \& Barrett, 2007; Bolhuis, Brown, Richardson and Laland, 2011). Due to limits of space in this paper these accounts are not discussed further, as the field of evolutionary aesthetics is most rooted in the classic and foundational interpretation of evolutionary psychology, as described in the main text.
} 
and thus emotional responses that motivated the individual concerned to remove itself from the threat (Pinker, 1997). One of the most fundamental emotional responses is the experience of beauty - where favourable conditions are present - and ugliness as its reverse - when environmental stimuli are perceived as harmful or threatening. Thornhill has concisely summarized this point as follows: "Beauty experiences are unconsciously realized avenues to high fitness in human evolutionary history. Ugliness defines just the reverse." (Thornhill, 2003: 9). Wilson similarly stated that human aesthetic propensities "play upon the circuitry of the brain's limbic system in a way that ultimately promotes survival and reproduction." (Wilson, 1984: 61).

The element of functionality with regard to environmental perception and affective experience is a recurring feature. Ruso and colleagues write that "human evolutionary aesthetics is in many ways the study of humble everyday lifepreferences and feelings evoked by a stimulus without self-conscious thought, and yet prevalent on an almost daily basis." (Ruso, 2003: 279). Kaplan similarly states that "aesthetics in this perspective is a functionally based way of responding to the environment." (Kaplan, 1992: 585) Such definitions make abundantly clear that research in evolutionary aesthetics inevitably involves a joint examination of cognition and emotion. Gazzaniga concisely summarized this as follows: "Aesthetics is a special class of experience, neither a type of response nor an emotion, but a modus operandi of "knowing about" the world. It is a sensation with an attached positive or negative evaluation." (Gazzaniga, 2009: 208).

Within evolutionary aesthetics, interest has focussed on two main subjects: aesthetic considerations made during mate choice, and evaluating habitats in terms of their suitability for prolonged occupation, often summarized under the subfield of environmental aesthetics. In both cases, immediately perceivable characteristics of an environment - including conspecifics present in it - can be indicators of more fundamental properties that may or may not be fitnessenhancing. Researchers in evolutionary aesthetics have tended to focus almost exclusively on the importance of visual perception, which explains why the vast majority of available theoretical and empirical studies also investigates this sensory modality. ${ }^{2}$

\footnotetext{
${ }^{2}$ But see e.g. Milinski, 2003 for an olfactory perspective.
} 
Researchers in environmental aesthetics are interested in uncovering which environments as a whole, or which particular features elicit favourable responses in observers, assuming that such positive appraisals are the product of evolved cognition, indicative of selection pressures during the Pleistocene. Three main hypotheses have dominated this field of research. In the savanna hypothesis, Orians and Heerwagen $(1992,1993)$ propose that the significant part of human Prehistory that was spent in the savanna environment of Eastern Africa is still reflected in current aesthetic preferences for landscape features. They describe the most essential human needs, at least during the Pleistocene, as having "to find adequate food and water and to protect themselves from the physical environment, predators, and hostile conspecifics." (1993: 140-141) Savanna environments are well suited for fulfilling these needs, as they often contain features like large trees, plant growth, water, focal points in semi-open spaces with changes in elevation and relatively unobstructed views of the horizon, which would have enabled a clear view of risks and opportunities in the immediate surroundings, as well as providing a degree of protection against possible harm (Orians 1980). Another notable hypothesis in the field is the prospect-refuge theory (Appleton 1975). It predicts that humans should seek out environments that provide a maximal balance of prospect - environmental features that enable, for example, spotting resources from a distance - and refuge - shelter opportunities in view of potential danger. Finally, Kaplan $(1989,1992)$ developed an information gathering model of environmental aesthetics, addressing the basic need to be able to extract relevant information from the surrounding environment while at the same time avoiding the risks that accompany treading in unknown territories. Based on a matrix of structural properties of an environment, such as coherence, complexity, legibility and mystery, it is argued that by assessing these properties, one should be able to understand an environment, as well as determine its exploratory potential.

Several features of these hypotheses have been tested empirically. In an analysis of recurrent features in western landscape painting and garden architecture, Orians and Heerwagen (1993) found preferences that are strongly consistent with the predictions made by the savanna hypothesis. In addition, they found that prospect-refuge imagery is related to the time of day depicted in a particular painting, with a stronger emphasis on refuge elements present when the scene was set during dusk or nightfall. Additionally, recent research has assessed the abovementioned and other findings from environmental aesthetics in 
contemporary contexts and in an applied manner, such as the role of nature imagery in advertising (Hartmann \& Apaolaza-Ibáñez 2010), and psychophysiological and behavioural effects of exposure to natural stimuli (e.g. Bringslimark, Hartig \& Patil, 2011, Donovan \& Prestemon, 2010, Nielsen \& Hansen, 2007).

The second main interest in evolutionary aesthetics is the process of sexual selection, and in particular the role of aesthetic considerations during courtship display and mate choice. Observations across a wide range of species yield numerous examples of sexually dimorphic traits, or phenotypic characteristics that differ between male and female organisms within a species. In practice, the males of a species are often the ones that possess complex, costly traits that appear paradoxical and even harmful from a survival perspective, but can relatively easily be explained as products of sexual selection (Miller, 2001). ${ }^{3}$

Two general frameworks have been proposed to account for the evolution of signalling traits as well as discriminatory abilities for assessing these traits (Barber, 1995, Miller, 2001). Good genes sexual selection encompasses a variety of ideas such as the handicap principle (Zahavi, 1975), parasite resistance theory (Hamilton \& Zuk, 1982) and perceivable developmental stability as the outcome of immunocompetence (Gangestad, Thornhill \& Yeo, 1994, Thornhill \& Gangestad, 1993, Watson \& Thornhill, 1994). The general argument is that phenotypic traits, such as morphological properties of an organism, can be indicative of underlying genetic quality and overall health. Two frequently studied phenotypic features in this regard are symmetry and averageness. The absence of symmetry in human bodies and faces is often indicative of developmental normalcy, and therefore the absence of parasites, bacteria and viruses that might interfere with regular development (Gangestad, Thornhill \& Yeo 1994). Averageness, most clearly recognizable in facial anatomy, is linked to heterozygosity which in turn correlates with better immunocompetence (Thornhill \& Gangestad, 1993, Watson \& Thornhill, 1994).

A second possibility would be to explain phenotypic traits as the outcome of a process of runaway selection (Fisher, 1930). Maintaining the gender bias of male display and female choice, this theory predicts that a preference arising in a female, in response to a male trait, can become caught in a feedback loop that

\footnotetext{
3 The bias of display traits among males and choice by females is explained by Trivers' parental investment theory (1972), which states that females' greater investment in gestation and childcare predicts greater choosiness when selecting mating partners, as insufficient partners entail much greater reproductive costs than for males, whose investment is a lot smaller.
} 
drives both the development of the trait in future generations of males, as well as the preference for this trait in female offspring. The original preference can be arbitrary, with no link between the trait and any underlying genetic quality or health, but runaway selection can also occur based on a pre-existing, functional preference such as the ones predicted by good genes sexual selection (Barber, 1995). Naturally, such a feedback loop comes to an end and stabilizes both the trait and the preference once they become harmful to the organisms' survival chances.

Along the lines of evolutionary psychological thinking on emotions as motivational agents for behavioural choices (e.g. Orians, 2001), evolutionary aesthetics research on mating generally proposes that aesthetic preferences for features such as symmetry and averageness of facial and bodily traits are in fact unconscious choices for health, developmental stability and good genes, as choices for these features result in higher-quality offspring, and thus would have gradually become endowed with neural rewards over the course of evolution. Since these are functional rather than arbitrary choices, the emphasis tends to be on good genes sexual selection.

In sum, research in evolutionary aesthetics can explain, through references to the evolution of adaptive neurocognitive mechanisms in mating and habitat contexts, why some structural properties appear to elicit neural reward and thus positive aesthetic appraisal in the form of beauty judgements. It then becomes possible to extent this research to art, or more specifically, to particular features that appear to be universally recurrent in terms of their aesthetic appeal. One way of doing so would be to map apparently universal aesthetic principles, such as symmetry, novelty and moderate complexity, and clarity (van Damme 1996). Additionally, it is possible to extend the signalling interpretation of human aesthetic features to artefacts, such as experiencing these as beautiful by - unconsciously assessing the resources and time spent on their creation (Voland, 2003).

\section{Evolutionary and philosophical aesthetics: the scene of a heated debate}

In a discussion of Nietzsche's biologically based aesthetics, Moore (2002) reconstructs how the latter's views did not constitute a major break with previous

\footnotetext{
${ }^{4}$ In line with this, Fisher developed the sexy son hypothesis, which states that a female's optimal mate choice may not be directly related to the immediate benefits she would receive from a male, such as resource provision, but may be aimed at producing sons with the highest chance of reproductive success.
} 
thought in philosophical aesthetics. In the mid 18th century, key figures such as Burke already investigated how aesthetic emotion may be explained by psychological and physiological principles. The turning point in this naturalistic approach came with the writings of Kant, who proposed a transcendental, idealistic aesthetic as opposed to a psychophysiological based one. Among the main elements of his aesthetic is the required disinterestedness of beauty judgements, referring to the absence of any interest in the functionality of a perceived object. A new impulse for naturalistic approaches to aesthetics, and eventually evolutionary aesthetics, did not arrive until the publication of Darwin's evolutionary theory in the mid 19th century (Moore, 2002). ${ }^{5}$

Despite the presence of naturalistic views on aesthetics in the history of this still predominantly philosophical discipline, researchers in the field often reluctantly respond to the advent of contemporary scientific theories and methods, such as those from evolutionary biology and psychology. The predominance of Kantian thought in philosophical aesthetics in particular seems to spark resistance against the evolutionary approach, as these two apparently conflict at various points. In the remainder of this paper, I will address three critiques sometimes uttered towards evolutionary aesthetics, and I will argue that evolutionary and more traditional approaches are not at odds, and even necessarily complementary. Content-wise, the focus will be on sexual selection related aesthetics rather than environmental aesthetics, as the former is predominant in current evolutionary aesthetics research.

\section{Functionality and aesthetic judgement}

In The Descent of Man and Selection in Relation to Sex, originally published in 1871, Darwin addressed the study of beauty in evolutionary terms by drawing parallels between humans and what appears to be aesthetic experience or judgement in the animal world. Upon tackling this subject, he writes:

This sense has been declared to be peculiar to man. I refer here only to the pleasure given by certain colours, forms, and sounds, and which may fairly be called a sense of the beautiful; with cultivated men such sensations are, however, intimately associated with complex ideas and trains of thought. When we behold a male bird elaborately displaying his graceful plumes or splendid colours before the female, while other birds, not thus decorated, make no such

\footnotetext{
${ }^{5}$ For a comprehensive overview of naturalism in the history of aesthetics, see Kreft 2007.
} 
display, it is impossible to doubt that she admires the beauty of her male partner. As women everywhere deck themselves with these plumes, the beauty of such ornaments cannot be disputed. As we shall see later, the nests of humming-birds and the playing passages of bowerbirds are tastefully ornamented with gayly coloured objects; and this shows that they must receive some kind of pleasure from the sight of such things. (1896: 92)

Darwin noted that seemingly aesthetic phenotypic features in the animal world are probably closely intertwined with the process of sexual selection, which creates selection pressures for, among other things, traits that are relevant for signalling reproductive quality to conspecifics of the opposite sex:

The sweet strains poured forth by many male birds during the season of love are certainly admired by the females, of which fact evidence will hereafter be given. If female birds had been incapable of appreciating the beautiful colours, the ornaments and voices of their male partners, all the labour and anxiety exhibited by the latter in displaying their charms before the females would have been thrown away; and this it is impossible to admit. (1896: 92)

Darwin's views are neatly in accordance with the present-day emphasis of evolutionary aesthetics on the emergence of the human aesthetic sense through mate choice. Research on this subject still tends to study the perception of physical attractiveness in conspecifics by making reference to unconscious yet innate discriminatory abilities to discern high quality mates from less suitable ones, such as the ones implied by the aforementioned process of good genes sexual selection, or by the handicap principle. ${ }^{6}$ While writing works such as On the Origin of Species (1859) and The Descent of Man (1871) Darwin himself was however unaware of the connection between processes such as natural and sexual selection, and their genetic substrates. He postulated the major theoretical principles of natural selection such as random variation, inheritance and selection, but did not possess sufficient knowledge of the mechanisms that were necessary for transmitting biological traits to future generations. He did however understand the possibility of a runaway process of sexual selection, where male display traits and female preferences for these traits evolve jointly and mutually strengthening, and thus co-evolve (Miller 2001).

\footnotetext{
${ }^{6}$ Good genes selection should be regarded as the predominant framework for understanding the functionality of aesthetic preferences, as a process such as runaway selection does not require a correlation between phenotypic traits observed and any corresponding genetic quality, although it could be equally responsible for the gradual evolution of aesthetic traits. See, for example, Boyd \& Richerson 1985, and Verpooten and Nelissen 2010, 2012.
} 
Darwin's uncertainty concerning the mechanisms that created male display traits in response to female aesthetic-like choice has been taken by critics to reveal a significant weakness in evolutionary aesthetics research proposing that females make aesthetic choices. Assuming that the absence of a clear explanation in The Descent of Man is suggestive of a faulty understanding of the potential aesthetic nature of female choice, O'Hear explores whether this aesthetic motivation is indeed invalid, or in other words, "the possibility that beauty is linked to other more clearly adaptive properties." (1997: 179) Specifically, he thinks female preferences may be directed towards favourable qualities such as strength and superiority. Striking ornamental display, for example, could be linked to territorial dominance, which would be the females' actual interest, rather than the aesthetic properties of any corresponding display traits. ${ }^{7}$ Famous cases such as the peacock's tail for example, typically explained as a good genes sexual selection motivation aesthetic choice, are regarded by critics as perhaps merely a fuctional preference for underlying health. O'Hear supports this argument by making reference to the work of Darwin's contemporary, the evolutionary biologist Alfred Russell Wallace.

Wallace developed a similar trajectory of evolutionary thought to account for the origin and development of species, but differed notably in opinion when it came to the principles of sexual selection. When discussing ornamentation, he distinguished between ornaments present in all organisms of a species, and ornaments present only in males. The first category was described as being a means for species recognition, thus explaining them independent of the mechanism of sexual selection. Predominantly male ornaments in turn, Wallace thought, were non-functional side-effects of an animal physiology aimed at bright colours and sounds, only constrained by natural selection. The increasingly outspoken presence of such ornaments during mating seasons or rituals was explained as the outcome of a stored surplus of energy. Females supposedly did not possess such ornaments as they needed to be a lot more camouflaged around their vulnerable offspring (Miller, 2001). Additionally, Wallace hypothesized that female choice was not actually based on aesthetic considerations, but rather on utilitarian motivations such as finding healthy partners.

\footnotetext{
7 "How might it be possible to decide between the view that aesthetic preference in animals is purely aesthetic or that what looks like aesthetic preference to us is really a preference for other qualities which go along with the aesthetic and are not chosen via any aesthetic appreciation?" (O'Hear, 1997: 180).
} 
In addition to sexual selectionist theory, it is necessary to consider the emergence of knowledge on genetics and inheritance. Unknown to Darwin, the basic rules of inheritance on a genetic level were established during his lifetime by the Czech friar and scientist Gregor Mendel, but it would take until the fourth and fifth decade of the twentieth century before these revolutionary paths of scientific discovery were joined together in what is now widely known as 'the modern synthesis' (e.g. Fisher, 1930). From an evolutionary aesthetics perspective, this synthesis allows for understanding aesthetic experiences and preferences in a functional way, as was described earlier. Any preference observed need not be arbitrary - although this may still be the case - but is potentially a naturally selected emotional, affective experience acting as a motivational agent for making functional choices.

These two considerations - functionality in aesthetic judgement and genetics at the basis of natural selection - make for a serious readjustment of original Darwinian thought on possible aesthetic motivations in non-human animal female choice for male ornamentation and display. As a consequence, what appears to be lacking in O'Hear's critique of Darwinian-based evolutionary aesthetics, is the recognition that good genes sexual selection explains how an aesthetic preference is linked to a more functional choice such as overall health and strength. While it is a fact that Darwin was not fully aware of such an unconscious motivation, this does not refute his suggestion that beauty judgement plays a role in display and mate choice, nor is it necessary to revive Wallace's views on sexual selection. Trying to do this is also not advisable in itself, given the numerous inconsistencies between Wallace's writings and what is currently known about the processes and mechanisms involved in the evolution and development of reproductively linked traits (Miller, 2001).

Of course the option still remains that elaborate peacocks' tails evolved through runaway sexual selection, which can in principle act upon arbitrary, non-fitness related traits. In this case, it could be true that the female preference for such tails can be sustained after accidentally arising - such as in the case of a mutation - if the preference is not harmful, i.e. if it doesn't correspond to a property in a male organisms that is severaly disadvantageous for survival and reproductive purposes (O'Hear, 1997). Yet this possibility overlooks the body of research providing insight into the precise connections between male phenotypic traits and their overall reproductive quality, as is evident from the aforementioned research on, for example, immunocompetence theory (see Barber, 1995). 
Such research indicates that it is unlikely that costly preferences for equally costly traits would persist if they were not compensated by functional benefits.

\section{Reductionism and the levels of explanation}

In The Descent of Man, Darwin acknowledged that a significant part of human aesthetic experience and judgement depends on elements of semantics, education and culture. While "man and many of the lower animals are alike pleased by the same colours, graceful shading and forms, and the same sounds," (1896: 93) he also thought that "no animal would be capable of admiring such scenes as the heavens at night, a beautiful landscape, or refined music; but such high tastes are acquired through culture, and depend on complex associations; they are not enjoyed by barbarians or by uneducated persons." (1896: 93) Indeed, "with cultivated men such sensations are, however, intimately associated with complex ideas and trains of thought." (1896: 93) Darwin thus recognized that human aesthetic experience is often, yet not always, tied up with rationality and cultivation, but precisely this element has been regarded by critics as conflicting with Kantian aesthetics. Scruton writes:

And one thing is surely right in Kant's argument, which is that the experience of beauty, like the judgement in which it issues, is the prerogative of rational beings. Only creatures like us with language, self-consciousness, practical reason, and moral judgement - can look on the world in this alert and disinterested way, so as to seize on the presented object and take pleasure in it. (2009: 33, original emphasis)

As such - at least if Kantian aesthetics is taken as a default position - it appears that Darwin surpasses the importance of rationality in human aesthetic judgement, thus making his parallels with the non-human world of animals apparently illegitimate. In this sense, evolutionary aesthetics is thought to be reductionist because it unjustly parallels humans with sometimes very distant animal relatives. A way out of this can perhaps be found in Davies's compromise position on the phylogenetic roots of the aesthetic, i.e. the extent to which we share our ability to aesthetically appreciate the outside world with non-human species. He rejects on the one hand the liberal position that all "pleasurable or unpleasurable perceptual experience" can be regarded as aesthetic, which would almost automatically equate that non-human animal aesthetic-like responses are the 
same as human ones (2012: 15). ${ }^{8}$ The other extreme take on aesthetic experience is the 18th century Enlightenment view, endorsed by Kant and others, which basically states that an aesthetic experience is contemplative, largely if not completely detached from utilitarian motivations, often directed towards the perception of formalist properties, and requiring a particular kind of interaction between imagination and understanding (Davies, 2012).

According to Davies, neither of these two positions appears sufficient to account for both non-human animal aesthetic-like responses, as well as human aesthetic experience that has been commonly described in philosophical aesthetics as being complemented with cognitive sophistication. Instead, seemingly aesthetic responses in birds, non-human primates and other species might perhaps be regarded as "affective states that are action-motivating" as "protoaesthetic, at least in the sense that human aesthetic responses arose from that kind of reaction." (2012: 10-11). This way, Davies acknowledges the phylogenetic roots of the human ability for aesthetic appreciation, while at the same time allowing for a distinction between the human and non-human animal nature of such appreciation - including the possibility, but not the necessity, of highly advanced cognitive involvement or detached contemplation in humans.

Another way of describing evolutionary aesthetics as reductionist is nature, is to regard the explanation of cultural and mental phenomena in biological terms as overly simplifying. More specifically, human aesthetic experience is often thought to be so complex that it cannot possibly be grasped in biological terms. Attempting to explain aesthetic experience and judgement by making reference to features such as neural reward mechanisms and psychological adaptations reduces, according to some, unjustly its cognitive and semantic richness (e.g. Van Gerwen, 2011).

Such concerns can relatively easily be addressed by describing an indeed very complex phenomenon such as aesthetic experience in terms of different explanatory levels. Reductionism is then not an attempt to reduce for example cultural or semantic elements to a biological level, but tries to account for these experiences with the help of more basic levels of explanation, in addition to higherlevel explanations. One such way of looking at a phenomenon at different levels

\footnotetext{
${ }^{8}$ When discussing aesthetic adaptations in humans, Symons has voiced a similarly liberal position when stating: "All adaptations are aesthetic adaptations, because all adaptations interact in some way with the environment, external or internal, and prefer certain states to others." (Symons pers. comm. In Thornhill, 2003: 9)
} 
is by studying aesthetic experience and judgement both in a cultural and philosophical way - focussing on individual experience, semantic content, imagination, etc. - as well as with bio-evolutionary methods - analyzing the neurobiological structure of the ability to appreciate objects, other individuals and the surrounding environment in terms of beauty and ugliness. ${ }^{9}$

\section{Cultural and interindividual differences in aesthetic preferences}

An evolutionary approach to aesthetics suggests that the human ability to appreciate objects, physical environments and animate beings in terms of beauty or ugliness is a universal propensity. However, this does not mean that all cultures must have the same aesthetic preferences. In a parallel with language, Davies (2012) explains that while our capacity for language learning and speaking is very likely an adaptation, this doesn't necessarily imply that all people worldwide must speak the same language. Instead, "we should be looking for widespread consensus over at least some aesthetic assessments within a culture and the possibility of coming to understand the different aesthetic preferences of other groups." (2012: 48) Aside from such a consensus - which may be a set of basic, universal aesthetic principles ${ }^{10}$ - evolution thus also allows for cultural variation.

Cultural differences in aesthetic preference may in itself rely on an evolved propensity to seek variation. In The Descent of Man, Darwin wrote:

As the great anatomist Bichat long ago said, if every one were cast in the same mould, there would be no such thing as beauty. If all our women were to become as beautiful as the Venus de' Medici, we should for a time be charmed; but we should soon wish for variety; and as soon as we had obtained variety, we should wish to see certain characters a little exaggerated beyond the then existing common standard. (1896:585)

${ }^{9}$ Within evolutionary research on human and non-human animal behaviour, the explanatory framework often used to integrate different levels of explanation is Tinbergen's four questions. These imply that a trait, for example a behaviour, can be studied at both a proximate and an ultimate level. The proximate level involves 'how' questions concerning how the trait develops in an individual, both by referring to the causal mechanisms and ontogeny, or how the trait develops over the course of an individuals lifetime. The ultimate level, the 'why' questions, refer to the phylogenetic history of a trait - how the presence of the trait within a species is related to its presence in other species - and functional, adaptive explanations for its emergence (Tinbergen, 1963).

${ }^{10}$ See, for example, Dutton 2002, van Damme 1996. 
The quest for variation can therefore explain why aesthetic preferences can change over time or across cultures, without any clear, functional reason (Cunnigham \& Shamblen, 2003). In some cases, changing social and ecological circumstances can alter preferences for particular traits, such as evidence of affluence and health in societies where nutritional conditions are poor. Correlations have also been found between a preference for neonate, softer traits in women's faces at times when the economy prospers, whereas opposite traits tend to be positively assessed during economic downfall (Pettijohn \& Tesser, 1999). Another reason that applies more specifically to temporal changes in aesthetic preference can be the tendency of a society's elite to maintain their external signals of high status by adopting new and different signals if the previous ones become increasingly average and are adopted by the society as a whole (Cunningham \& Shamblen, 2003).

In attempting to understand how evolutionary aesthetics can explain interindividual differences, it is relevant to include neurocognitive research on this subject. ${ }^{11}$ By studying individuals' brains in a variety of conditions and with different sets of stimuli, it becomes possible to understand how such differences in aesthetic appreciation work on a neurobiological level, and consequentially, how they eventually become clear in aesthetic experience and judgement on a more conscious level. fMRI research by Kirk and colleagues (2009) with groups of architects and non-architects found that the level of expertise present influences the cognitive processing of relevant stimuli, in this case architectural creations, but also the amount of neural rewards evoked by these stimuli. This means that an individual more familiar with a particular kind of representations can experience heightened aesthetic responses. Such an effect may be due to the mechanism of neuroplasticity, which broadly refers to the brain's capacity to establish new neural connections following new experiences or the perception of representations, while deleting old or less useful ones. In this manner, knowledge is again joint with emotion in order to produce aesthetic effects (Jacobsen, 2010).

11 Concerning individual variation, it is important to note that the process of evolution through natural or sexual selection precisely takes such individual variation as a starting point. If there was no variation in a particular trait, for example the extent to which an organism is capable of assessing the reproductive quality of a conspecific in aesthetic terms, evolution could not act upon the trait to select more successful variations to maintain in future generations. 


\section{Conclusion}

In this paper, I outlined the methodological apparatus and thematic focus of evolutionary aesthetics, describing how it presents the human ability to express evaluative emotional judgement in terms of beauty and ugliness as an evolved motivational mechanisms with functional underpinnings. Three important critiques of evolutionary aesthetics were addressed, only representing a limited set of questions that can be asked at the intersection of evolutionary and more traditional humanities approaches to this subject. I argued that comments such as the one made by O'Hear concerning the potential functional, rather than aesthetic motivation at play in female choice reflects a one-sided interpretation of original Darwinian aesthetics, losing its presumed validity in the light of fundamental additions to Darwinian thought such as the ones made in the extended synthesis. Additionally, I pointed out that the often feared reductionist agenda of evolutionary aesthetics is valid in scientific terms, i.e. in trying to approach our ability for aesthetic judgement on a more fundamental, biological level. Finally, I provided suggestions in support of the idea that looking at the evolutionary foundations of our aesthetic sense does not equal stating that there is no room for cultural or interindividual variation. In this regard, neurocognitive research may prove to be particularly enligthening for our understanding of aesthetic experience and judgement on multiple levels.

\section{References}

Aiken N.E. (1999). Literature of Early "Scientufic" and "Evolution" Aesthetics. [In:] B. Cooke, F. Turner (eds.). Biopoetics. Evolutionary Explorations in the Arts. Kentucky, pp. 417-431.

Allesch C.G. (2001). Fechner's Aesthetics - a Provocation? Lecture Given at the Symposium in Honour of Gustav Fechner's 200th Anniversary, Leipzig, 19-20 October 2001.

Appleton J. (1975). The Experience of Landscape. London.

Barber N. (1995). The Evolutionary Psychology of Physical Attractiveness: Sexual Selection and Human Morphology. "Ethology and Sociobiology", 16, pp. 395-424.

Bolhuis J., Brown G.R., Richardson R.C., Laland K.N. (2011). Darwin in Mind: New Opportunities for Evolutionary Psychology. "PLoS Biology", 9, el001109. doi:10.1371/journal.pbio.1001109. Boyd R., Richerson P.J. (1985). Culture and the Evolutionary Process. Chicago.

Bringslimark T., Hartig T., Patil G.G. (2011). Adaptation to Windowlessness: Do Office Workers Compensate for a Lack of Visual Access to the Outdoors? "Environment and Behavior", 43, pp. 469-487. 
Cosmides L., Tooby J., Barkow J.H. (1992). Introduction: Evolutionary Psychology and Conceptual Integration. [In:] J.H. Barkow, L. Cosmides, J. Tooby (eds.). The Adapted Mind. Evolutionary Psychology and the Generation of Culture. New York, pp. 3-18.

Cunningham M.R., Shamblen, S.R. (2003). Beyond Nature Versus Culture: a Multiple Fitness Analysis of Variations in Grooming. [In:] E. Voland, K. Grammer (eds.). Evolutionary Aesthetics. Berlin, pp. 201-237.

Darwin C. [1859] (1861). On the Origin of Species by Means of Natural Selection, or the Preservation of Favoured Races in the Struggle for Life. New York.

Darwin C. [1871] (1896). The Descent of Man and Selection in Relation to Sex. New York.

Davies S. (2012). The Artful Species. Art, Aesthetics, and Human Evolution. Oxford.

Dobzhansky T. (1973). Nothing in Biology Makes Sense Except in the Light of Evolution. "American Biology Teacher", 35, pp. 125-129.

Donovan G.H., Prestemon J.P. (2012). The Effect of Trees on Crime in Portland, Oregon. "Environment and Behavior", 44, 3-30.

Dunbar R.I.M., Barrett L. (2007). Evolutionary Psychology in the Round. [In:] R.I.M. Dunbar L. Barrett (eds.). The Oxford Handbook of Evolutionary Psychology. Oxford, pp. 3-9.

Dutton D. (2002). Aesthetic Universals. [In:] B. Gaut, D. McIver Lopes (eds.). The Routledge Companion to Aesthetics. London, pp. 203-214.

Fisher R.A. (1930). The Genetical Theory of Natural Selection. Oxford.

Gangestad S.W., Thornhill R., Yeo R.A. (1994). Facial Attractiveness, Developmental Stability, and Fluctuating Asymmetry. "Ethology and Sociobiology", 15, pp. 73-85.

Gazzaniga M. (2009). Human. The Science Behind What Makes Us Unique. New York.

Hamilton W.D., Zuk M. (1982). Heritable True Fitness and Bright Birds: A Role for Parasites. "Science", 218, 384-387.

Hartmann P., Apaolaza-Ilbáñez V. (2010). Beyond Savanna: An Evolutionary and Environmental Psychology Approach to Behavioral Effects of Nature Scenery in Green Advertising. "Journal of Environmental Psychology", 30, pp. 119-128.

Heerwagen J., Orians G. (1993). Humans, Habitats, and Aesthetics. [In:] S.R. Kellert, E.O. Wilson (eds.). The Biophilia Hypothesis. Washington D.C., pp. 138-172.

Jacobsen T. (2010). Beauty and the Brain: Culture, History and Individual Differences in Aesthetic Appreciation. "Journal of Anatomy", 216, pp. 184-191.

Kaplan R., Kaplan, S. (1989). The Experience of Nature: a Psychological Perspective. Cambridge.

Kaplan S. (1992). Environmental Preference in a Knowledge-seeking, Knowledge-using Organism. [In:] J.H. Barkow, L. Cosmides, J. Tooby (eds.). The Adapted Mind. Evolutionary Psychology and the Generation of Culture. New York, pp. 581-600.

Kirk U., Skov M., Christensen M.S., Nygaard N. (2009). Brain Correlates of Aesthetic Expertise: a Parametric fMRI Study. "Brain and Cognition", 69, pp. 306-315.

Kreft L. (2007). The Second Modernity of Naturalist Aesthetics. "Filozofski Vestnik", 18, pp. 83-98.

Milinski M. (2003). Perfumes. [In:] E. Voland, K. Grammer (eds.). Evolutionary Aesthetics. Berlin, pp. 325-339.

Miller G. (2001). The Mating Mind. How Sexual Selection Shaped the Evolution of Human Nature. London.

Moore G. (2002). Art and Evolution: Nietzsche's Philosophical Aesthetics. "British Journal for the History of Philosophy", 10, pp. 109-126. 
Nielsen T.S., Hansen K.B. (2007). Do Green Areas Affect Health? Results from a Danish Survey on the Use of Green Areas and Health Indicators. "Health \& Place", 13, pp. 839-850.

O'Hear A. (1997). Beyond Evolution. Human Nature and the Limits of Evolutionary Explanation. Oxford.

Orians G. (1980). Habitat Selection: General Theory And Applications To Human Behavior. [In:] J.S. Lockard (ed.). The Evolution of Human Social Behavior. Amsterdam, pp. 49-66.

Orians G. (2001). An Evolutionary Perspective on Aesthetics. "Bulletin of Psychology and the Arts", 2, s.p.

Orians G., Heerwagen J. (1992). Evolved Responses to Landscapes. [In:] J.H. Barkow, L. Cosmides, J. Tooby (eds.). The Adapted Mind. Evolutionary Psychology and the Generation of Culture. New York, pp. 55-580.

Pettijohn T.F. Tesser A. (1999). Popularity in Environmental Context: Facial Feature Assessment of American Movie Actresses. "Media Psychology", 1, pp. 229-247.

Pinker S. (1997). How the Mind Works. London.

Ruso B., Renninger L., Atzwanger K. (2003). Human Habitat Preferences: A Generative Territory For Evolutionary Aesthetics Research. [In:] E. Voland, K. Grammer (eds.). Evolutionary Aesthetics. Berlin, pp. 279-294.

Scruton R. (2009). Beauty. New York.

Symons D. (1992). On the Use and Misuse of Darwinism in the Study of Human Behavior. [In:] J.H. Barkow, L. Cosmides, J. Tooby (eds.). The Adapted Mind. Evolutionary Psychology and the Generation of Culture. New York, pp. 137-159.

Thornhill R. (2003). Darwinian Aesthetics Informs Traditional Aesthetics. [In:] E. Voland, K. Grammer (eds.). Evolutionary Aesthetics. Berlin, pp. 9-38.

Thornhill R., Gangestad S.W. (1993). Human Facial Beauty: Averageness, Symmetry, And Parasite Resistance. "Human Nature", 4, pp. 237-269.

Tinbergen N. (1963). On Aims and Methods of Ethology. "Zeitschrift für Tierpsychologie", 20, pp. 410-433.

Trivers R. (1972). Parental Investment and Sexual Selection. [In:] B. Campbell (ed.). Sexual Selection and the Descent of Man. Chicago, pp. 136-179.

Van Damme W. (1996). Beauty in Context. Towards an Anthropological Approach to Aesthetics. Leiden.

Van Gerwen, R. (2011). Esthetische normativiteit. Tegen empirische en evolutionaire "verklaringen". „Algemeen Nederlands Tijdschrift voor Wijsbegeerte“, 103, 126-138.

Verpooten J., Nelissen M. (2010). Sensory Exploitation and Cultural Transmission: The Late Emergence of Iconic Representations in Human Evolution. "Theory in Biosciences", 129, pp. 211-221.

Verpooten J., Nelissen M. (2012). Sensory Exploitation: Underestimated in the Evolution of Art As Once in Sexual Selection? [In:] K.S. Plaisance, T.A.C Reydon (eds.). Philosophy of Behavioral Biology. "Boston Studies in the Philosophy of Science", 282, pp. 189-216.

Voland E. (2003). Aesthetic Preferences in the World of Artfacts - Adaptations for the Evaluation of Honest Signals? [In:] E. Voland, K. Grammer (eds.). Evolutionary Aesthetics. Berlin, pp. 239-260.

Watson P.J., Thornhill R. (1994). Fluctuating Asymmetry and Sexual Selection. "Tree", 9, pp. 21-25.

Wilson E.O. (1984). Biophilia. Cambridge.

Zahavi A. (1975). Mate Selection: a Selection for a Handicap. "Journal of Theoretical Biology", 53, pp. 205-214. 